\title{
The influence of exogenous testosterone and corticosterone on the social behavior of prepubertal male rats
}

\author{
MICHAEL J. MEANEY \\ Rockefeller University, New York, New York 10021 \\ and \\ JANE STEWART \\ Concordia University, Montreal, Quebec H3G 1M8, Canada
}

\begin{abstract}
Male rat pups were injected daily between 26 and 40 days of age with either 200 micrograms of testosterone propionate (TP), 300 micrograms of corticosterone (CORT), or with the oil vehicle. Observations were made daily of the animals while in mixed-sex groups of eight. The results showed that while TP-injected pups mounted more often than did the other males, neither TP nor CORT affected the frequency with which male pups initiated play-fights or the frequency with which they "dominated" or "submitted to" other pups once engaged in a play-fight. Thus, while the results of previous work have demonstrated that both TP and CORT exert an organizational effect on the play-fighting of male pups, neither of these hormones appears to have an activational influence on play-fighting.
\end{abstract}

Male rat pups engage in more play-fighting than do their female peers (Meaney \& Stewart, 1981a; Poole \& Fish, 1976). A similar sex difference in social play has been observed in several primate species (see Mitchell, 1979). In both the rhesus monkey (Goy, 1978) and the Norway rat (Meaney \& Stewart, 1981b;Olioff \& Stewart, 1978), females treated with either testosterone or dihydrotestosterone during the critical period for sexual differentiation engaged in play-fighting at rates that were comparable to those of normal males. In male rat pups, castration on either Day 1 or Day 6 reduced the frequency of play-fighting to levels that were indistinguishable from those of normal females, whereas castration after Day 10 had no such effect (Beatty, Dodge, Traylor, \& Meaney, 1981; Meaney \& Stewart, 1981b). Similarly, in the rhesus monkey, the postnatal treatment of females with testosterone did not influence the frequency with which they engaged in play-fighting (Joslyn, 1973). Thus, in both the rhesus monkey and the Norway rat, early exposure to androgens appears to be sufficient for eliminating the sex difference in playfighting (i.e., androgens have an organizational effect), whereas circulating testosterone during the prepubertal period does not appear to be necessary for the expression of male-typical levels of play-fighting (i.e., androgens have no activational effect).

This work was supported by Grant A0156 from the Natural Sciences and Engineering Research Council of Canada to J. Stewart. M. J. Meaney was supported by a predoctoral fellowship from the Ministère de l'Education, Province du Québec. The authors wish to thank Gabi Galler for her help in collecting the data presented in this paper.
Androgens are not the only hormones that have been found to exert an organizational effect on play-fighting. Meaney, Stewart, and Beatty (1982) found that corticosterone (CORT) administered to male pups on Days 1 and 2 or on Days 3 and 4 of life decreased the frequency with which they engaged in play-fighting. CORT administerations to males on Days 9 and 10 or to females at any of these ages had no effect on play-fighting. It is not known, however, whether CORT also exerts an activational effect on play-fighting, or, as with androgens, the effect is limited to the neonatal period.

In this paper, we report the results of an experiment in which male pups housed in groups of eight were injected daily with TP, CORT, or oil. The issue here is that of the potential activational effects of these steroids. Although the evidence certainly suggests that there is no activational effect of testosterone on play-fighting, the question merits a direct test. The question of activational effect of CORT has simply not been addressed.

\section{METHOD}

The animals used in this experiment were 21 male LongEvans hooded rats. The animals were taken from four litters of females mated at the Concordia University animal colony. At 23 days of age, the animals were separated from their mother, weighed, and placed into four groups of eight animals each. Each group was composed of five or six male pups (at least one of each treatment) and two or three female pups. The four groups were housed in $51 \times 33 \times 26 \mathrm{~cm}$ cages. The animals were maintained on a $12-\mathrm{h}$ light/12-h dark schedule (lights out at $1200 \mathrm{~h})$.

The animals were injected daily from 26 to 40 days of age with 200 micrograms of TP, 300 micrograms of CORT, or the 
oil vehicle. Steroids were delivered in $.05 \mathrm{ml}$ of peanut oil using subcutaneous injections. The injections were done at $0900 \mathrm{~h}$ on each day, approximately $4 \mathrm{~h}$ before the observations began.

The behavior of the animals was scored using a focalobservation technique (see Altmann, 1974). Observations were conducted within the first $4 \mathrm{~h}$ of the dark cycle. The animals were observed daily between 26 and 40 days of age. Each day, each male pup in each group was observed for 20 sessions. Each session lasted $15 \mathrm{sec}$. This period was chosen because it was sufficient in length to describe the ongoing social behavior of a pup and yet brief enough to allow for several observation sessions per day. Within each group, the male pups were observed sequentially until all had been observed for one 15 -sec session each. The observer then changed to a second group and repeated the procedure until every pup had been observed for 20 sessions.

During each observation session, the observer focused on one pup and scored the following behaviors: Pouncing-One pup lunges at another with its forepaws extended outward. It is the forepaws that first make contact with the other animal. Onthe-back posture-One animal lies on its back fully exposing its ventral surface to another animal. On-top posture-One animal positioned over another animal with its forepaws placed on the second animal. Mounting-This included the full mounting pattern of one animal approaching another animal, placing its forepaws on that animal, and executing pelvic thrusts. We scored mounting behavior largely as a measure of the effectiveness of the TP injections, since this treatment has been shown to induce precocial sexual behavior in prepubertal rats (Baum, 1972).

\section{RESULTS}

The frequency with which each male pup was observed to be engaged in each behavior was calculated over the 15 days of observation (i.e., Days 26-40). These data are summarized in Table 1. The data for each behavior were analyzed across the three treatment groups $(n=7$ in each group) using a Kruskal-Wallis $\mathrm{H}$ test (Kruskal \& Wallis, 1952). Post hoc analysis was performed using Mann-Whitney U tests (Seigel, 1956).

The statistical analysis revealed that there were no significant treatment effects on any of the measures of play behavior (pouncing, $\mathrm{H}=2.2$, n.s.; on-top posture, $\mathrm{H}=2.8$, n.s.; on-the-back posture, $\mathrm{H}=1.5$, n.s.). As expected, there was a significant treatment effect on mounting $(H=10.7, p<.005)$ that was due to the higher observed frequency of mounting in TP-treated males than in CORT-treated males $(\mathrm{U}=7.5, \mathrm{p}<.02)$ or in oil-treated males $(U=2, p<.005)$.

Table 1

Median (M) and Range (R) of Scores for the Various Behaviors in Corticosterone-Treated (CORT), Testosterone-Treated (TP), and Oil-Treated Animals Over Days 26-40

\begin{tabular}{|c|c|c|c|c|c|c|c|c|}
\hline \multirow[b]{3}{*}{ Group } & \multicolumn{8}{|c|}{ Behavior } \\
\hline & \multicolumn{2}{|c|}{ Pouncing } & \multicolumn{2}{|c|}{ Mounting } & \multicolumn{2}{|c|}{ On Top } & \multicolumn{2}{|c|}{ On the Back } \\
\hline & M & $\mathbf{R}$ & $\mathbf{M}$ & $\mathbf{R}$ & M & $\mathbf{R}$ & $\mathbf{M}$ & $\mathbf{R}$ \\
\hline CORT & 40 & $29-59$ & 7 & $4-23$ & 24 & $18-42$ & 1.9 & $18-32$ \\
\hline TP & 37 & $25-62$ & 22 & $8-29$ & 23 & $16-32$ & 19 & $7-23$ \\
\hline Oil & 36 & $23-58$ & 4 & $1-17$ & 19 & $11-28$ & 19 & $9-23$ \\
\hline
\end{tabular}

\section{DISCUSSION}

The results of this experiment reveal that neither exogenous TP nor CORT influenced the play-fighting of prepubertal male rats. While there was a pronounced effect of TP treatment on mounting, there was no evidence (e.g., distress vocalizations, wounds, etc.) of TP-induced aggressive behavior such as that reported by Levy and King (1953) and by Svare and Gandleman (1975) in experiments with TP-treated prepubertal mice. This is not surprising, inasmuch as Meaney and Stewart (1981a) had found that even after puberty (i.e., after the onset of mounting), male rats living in intact groups continued to play-fight and showed lit tle evidence of aggressive behavior.

These results lend further support to what is now the strong conclusion that circulating levels of androgens do not influence the play-fighting of male pups. Specifically, the results of this study show that the failure to detect a difference between the frequency of play-fighting observed in neonatally androgenized females or in weanling castrates and that observed in intact males was not due simply to the presence of low levels of testosterone in the intact males. Even daily injections of TP, in a dose sufficient to induce precocious mounting, did not affect playfighting. The same conclusion now seems to apply to CORT. Male pups injected daily with CORT did not differ in their play-fighting from oil-treated males. Thus, while both CORT and TP exert an organizational effect on play-fighting, neither seems to produce an activational effect.

\section{REFERENCES}

Altmann, J. Observational study of behavior: Sampling methods. Behaviour, 1974, 48, 1-41.

BAUM, M. J. Precocious mating in male rats following treatment with androgen or estrogen. Journal of Comparative and Physiological Psychology, 1972, 78, 356-367.

Beatty, W. W., Dodge, A. M., Traylor, K. L., \& Meaney, M. J. Temporal boundary of the sensitive period for hormonal organization of social play in juvenile rats. Physiology \& Behavior, 1981, 26, 241-243.

Goy, R. W. Development of play and mounting behavior in female rhesus virilized prenatally with esters of testosterone or dihydrotestosterone. In D. J. Chivers \& J. Herbert (Eds.), Recent advances in primatology (Vol. 1). Behavior. New York: Academic Press, 1978.

JoslyN, W. D. Androgen-induced social dominance in infant female rhesus monkeys. Journal of Child Psychology and Psychiatry, 1973, 14, 137-145.

KRUSKAL, W. H., \& WALLIS, W. A. Use of ranks in one-criterion variance analysis. Journal of the American Statistical Association, 1952, 47, 583-621.

LEVY, J. V., \& KING, J. A. The effects of testosterone propionate on fighting behavior in young male C56BL/10 mice. Anatomical Record, 1953, 117, 562-563.

Menney, M. J., \& Stewart, J. A descriptive study of social development in the rat (Rattus norvegicus). Animal Behaviour, $1981,29,34-45$. (a)

Meaney, M. J., \& STEwart, J. Neonatal androgens influence the social play of prepubescent rats. Hormones and Behavior, 1981, 15, 197-213. (b)

Meaney, M. J., \& Stewart, J., \& BeatTy, W. W. The influence of neonatal glucocorticoids on the social play of prepubertal rats. Hormones and Behavior, 1982, 16, 475-491.

Mitchell, G. Behavioral sex differences in nonhuman primates. New York: Van Nostrand, 1979.

Oliof, M., \& Stewart, J. Sex difference in the play behavior of prepubescent rats. Physiology \& Behavior, 1978, 20, 113-115.

Poole, T. B., \& FisH, J. An investigation of individual, age, 
and sexual differences in the play of Rattus norvegicus (Mammalia: Rodentia). Proceedings of the Zoological Society of London, 1976, 179, 249-260.

Seigel, S. Non-parametric statistics. McGraw-Hill: New York, 1956.
Svare, B. B., \& Gandleman, R. Aggressive behavior in juvenile mice: Influence of androgen and olfactory stimuli. Developmental Psychobiology, 1975, 8, 405-415.

(Received for publication February 22, 1983.) 